\title{
The Application of High and New Material in Sports
}

\author{
Xiangqin Song \\ College of P.E. and Sports, \\ Beijing Normal University, \\ Beijing, China \\ songxq1978@126.com
}

\begin{abstract}
Sports are based on the progress of science sports, and it relies on the development of materials science. Modern information technology and new materials is changing the human production and way of life. High and new materials in sports play a vital role in the process of development.
\end{abstract}

Keywords-high and new material; sports; application

\section{INTRODUCTION}

Sports is a window of modern science and technology, it represents a country's level of development of science and technology. In today's world of sports competition is essentially the competition of science and technology, advanced and novel materials is one of the important conditions to improve sports science and technology level. Modern sports from natural, simple equipment and activities gradually developed into the standardization, standardization, using modern materials equipment and venues. Sports are based on the progress of science sports, and it relies on the development of materials science. Modern information technology and new materials is changing the human production and way of life. High and new materials in sports play a vital role in the process of development.

\section{NEW MATERIALS USED IN SPORTS EQUIPMENT}

Nowadays, high and new material has been widely used in the manufacturing industry, which makes a variety of sports equipment used in the national fitness activities more frequently, and more suitable for the activities of people, to some extent this has accelerated the development of nationwide fitness campaign. In general, on the sports equipment has applied to the new material have the following characteristics.

(1) Simple convenient, quite strong and feel good. Tennis racket, for example, at the early time the production material is wood and metal materials. The tennis racket made of this material is rough. Now the production material is glass fiber reinforced material, the use of this material not only can reduce weight, also can enhance shock absorption, and have a better feel. The production of golf clubs before material is persimmon trees, even if the production of golf clubs more exquisite, also not heavy, but it has poor toughness, when swinging a golf club had to wield it would feel to be big, then golf club is made of light alloy, which obviously increase the hardness of the club, but it also has shortcomings, that is a very poor fatigue resistance performance, and the price is too expensive, can only consumption in the high society crowd. But now, golf clubs is made of carbon fiber, mixed with graphite and composite materials. The club is not only simple, good flexibility, but also because of the rod head heavy cue light, can improve the player's swing speed. Another example, pole is made of wood at the first. But because the wood is easy to be broken, people began to use bamboo to make good elastic pole, and also very light, so people began to use the bamboo, but also because put it into the game, will greatly improve the athlete's result, from 1912 to 1912, a total of 10 people created a new world record, but also more than 10 times, a total of 16 times. During the Second World War, many European and American countries began to study of lightweight alloy pole, then but also for the emergence of the poles, gradually replaced the bamboo's status in the world. Later has now become a fiberglass rod, pole is made of glass fiber and resin. In 1960 , one is to use glass rod of the United States to break a world record. Since then, the level of the pole vault had greatly improved. In 1963, people broke the world record for 3 times, the athletes' performance and the corresponding improved $11 \mathrm{~cm}$; Also broke the world record in 1963, four times, until the end of the $1970 \mathrm{~s}$, in the project of the United States has maintained its advantages.

(2) Strong toughness and good security. Ski boots at the early time, for example, is made of polyurethane, use the material production ski boots is easy to slide in when athletes ankle injury. But now the production of ski boots is nylon, made of this material not only let the quality light, but also has strong rigidity, athletes will feel very smart and safe in use. Before fishing rod is made of bamboo and aluminum, made of these two kinds of material rod is easy to break, but now to make the rod use of carbon fiber reinforced composite materials, made of rod is bow, and has a strong toughness, not easily broken. Navigation and mountaineering enthusiasts often use the ropes, they used the hemp rope, it's very dangerous to use, but now making rope material is graphite, made of carbon fiber ropes, not only wear resistant and corrosion resistant, but also has the very high security.

(3) The use of long maturity, strong shock resistance and corrosion resistance. Navigation, for example, the production of sports equipment materials is made of polyethylene fiber reinforced vinyl ester composite 
material, made of nautical sports equipment not only light weight, but also has a strong resistance to impact, not susceptible to corrosion of sea water.

(4) The various characteristic increased the activities of interest. Some golf, for example, is made of light-emitting materials, so if the game is going to very late, that on the surface of the ball will be issued a green light, which makes the game shouldn't be terminated because it was very late. Because using the luminous drift, it can enhance the pleasure of fishing enthusiast.

\section{NEW MATERIALS APPLICATION IN SPORTS EQUIPMENT}

(1) Sportswear with respiratory function and can automatically adjust the temperature of the strip. On the clothes they use nylon taffeta coated amino acid polymer, it has high performance of waterproof, windproof, but its permeability rate and 2 times for general fabrics, due to the amino acid is a polymer is one of the ingredients of the protein in human skin, so it has a similar to "breathe" skin moisture absorption and moisture proof function.

There is a way to use the weather memory polymer coated nylon or polyester fabrics, emerging in hot weather, the fiber will automatically open, let the sweat discharge; when the weather is cold, the fiber will automatically shut down, to keep warm.

(2) New material swimsuit. In 1972, the wool bathing suit at the Munich Olympics attracted everybody's attention. In 1974, the United States DuPont invented a kind of material which has the function of two-way adjustable, which will produce a bathing suit without rubber layer, made swimsuit in two directions are able to scale, which can prevent the swimsuit after elongation will flow into the water too much, it to a certain extent, improve the performance of the swimsuit. At the Montreal Olympics, this does not contain the rubber bathing suit also attracted everybody's attention. At the Seoul Olympic Games, the company developed a swimsuit, named Hercules this swimsuit production material is super fine nylon fiber and polyurethane fiber, the costumes are much thinner than a human hair, and its weight is only $150 \mathrm{~g}$, not more than $200 \mathrm{~g}$. This bathing suit not only on the smoothness, or in terms of scalability, suits well than before, more than ever before swimsuit reduces the resistance of water, about $10 \%$, and the United States because of using the research of the new Hercules swimsuit, and has achieved unprecedented success. The growing emergence of new materials, let the bathing suit has a new development direction, that is the concave and convex, improve the body show the streamlined body let athletes; Made a bathing suit to let the water flow along the surface of the body; Prevent water from entering the bathing suit, once into the water, can make its effective dicharge.

(3) The application of new materials in sports shoes. As people on the practice of track and field sports, the athletes' competitive level is improving; their tournament competition is increasingly fierce. All want to break the world record, but you need to do this, not only is the work of the athletes, even on the running shoes also has the ability to fight. Obtained through practice shows that when the weight of the running shoes to add $100 \mathrm{~g}$, so the consumption of athletes 'physical ability will increase by $1 \%$. If it is in the $100 \mathrm{~m}$ sprint, then top athlete's performance will only a little difference. At this time, which can reduce the weight of the spikes, is very important. And Nike's strong company, for example, studied the subject, they thought to reduce the weight of the shoes, that needs to be under the premise that does not change the quality of the cleats, reduce the weight of the more the better, therefore, there are a lot of countries researchers want to use some new material to make shoes. Events and the characteristics of different venues, so they use boots are also different, this need people specially designed. In 1991, Mizuno Company has made a pair of running shoes, only $115 \mathrm{~g}$ this pair of shoes is specially made for sprinters Lewis; this will reduce the $20 \mathrm{~g}$ of shoes. It also makes Lewis world record was broken on the Seoul Olympic Games, from the son won a gold medal.

\section{SUMMARY}

High and new materials constantly emerging also will continue to be used in sports equipment manufacturing. The main trend is as follows: (1) with the improvement of manufacturing technology and process, production equipment will reduce the cost, instrument will spread and popularization of the new material. (2) The use of new materials in the sports and is only part of the project, many projects in the future will use new materials to help athletes improve performance. (3) The latest model of aerospace materials will be widely applied to the production of the sports equipment.

\section{CORRESPONDING AUTHOR}

Xiangqin Song, songxq1978@126.com, 13810523765

\section{REFERENCES}

[1] Zhou Biao. The effect of sports equipment using advanced materials on the development of competitive sports. Journal of Jiamusi institute of education [J], 2009, 3:121-122.

[2] Wang Shansheng, Wangfen. Gold is behind the science and technology war $[\mathrm{M}]$. Beijing: Beijing sport university Publisher, 1997:6-10.

[3] Zhao Bingpu, Gao jian. Sports dependence on materials and problems [J]. Journal of China Sports science and technology, 1997 (9): 40-42.

[4] Peng Xuehan. Modern new material technology and the improvement of sports [J]. Journal of Fujian sports Science and technology, 2000, 12 (5): 4 -8.

[5] Du Xiyan. Fiber reinforced composite material application in sports equipment [J]. Journal of Shandong Textile science and technology, 2007, (1): 50 -2. 